\title{
Diaspora, temporality, and politics: Promises and dangers of rotational time
}

\section{Patrick Eisenlohr}

To cite this article: Patrick Eisenlohr (2020) Diaspora, temporality, and politics: Promises and dangers of rotational time, Sikh Formations, 16:1-2, 166-171, DOI: 10.1080/17448727.2018.1545188

To link to this article: https://doi.org/10.1080/17448727.2018.1545188

册Published online: 16 Nov 2018.

Submit your article to this journal

凹 Article views: 50

Q View related articles ๘

View Crossmark data \ulcorner

4 Citing articles: 1 View citing articles 


\title{
Diaspora, temporality, and politics: Promises and dangers of rotational time
}

\author{
Patrick Eisenlohr \\ University of Göttingen, Göttingen, Germany
}

When during the 1990s diaspora studies experienced their first boom, there was much enthusiasm about diasporas' cross-border properties and connections as a possible antidote against the purisms and exclusions of homogenizing nation-states. At the time, many academics considered the latter an increasingly obsolete species in a world apparently shaped by growing trends towards globalization on multiple levels. Since then, political events around the world have forcefully shown that the nation-state is alive and well and shows no signs of disappearance. Closely connected to this point is the realization that there is no historical teleology behind globalization processes, as the latter can be limited or reversed any time. It also dawned on scholars engaged in research on diasporas that diasporic politics and ways of life do not always result in hybrid and fluid forms of identification. It became obvious that diasporic ways of life could not only comfortably coexist with purist identifications and hierarchies. Such ways of life can also even generate ethnic, religious, and racial forms of exclusion.

In this contribution, I would like to take up Michael Nijhawan's focus on the embodied aspects of memory and time he elaborates so insightfully in The Precarious Diasporas of Sikh and Ahmadiyya Generations, specifically his invocation of, via Veena Das's work (2007, 100), of Bergson's distinction between translational and rotational time (Nijhawan 2016, 51). Drawing on examples from my own work on Hindu diasporas in Mauritius and the ways in which processes of diasporization in Mauritius have been incited and sanctioned by a specific Mauritian postcolonial regime of nation-building, I would like to point to the affordances that Bergson's "rotational" movement in memory provides for the making of memories of displacement.

Diasporas do not come into being by the sheer fact of displacement but are the outcome of processes of diasporization that set in after such real or imagined displacements have occurred. Since diasporas always involve a reworking of actual or imagined experiences of spatial and temporal displacement across generations, they can also be described as chronotopes. Such reworking of temporality is a central part of the practices and institutions that generate a sense of being in the diaspora. Being in diaspora often defies linear, "empty homogenous" forms of time tied to a notion of progress that is widely considered a hallmark of modernity. Instead, the practices, rituals and institutions that perform the work of diasporization frequently institutionalize other, alternative forms of temporality centered on the theme of the co-presence of ancestors and the worlds 
they left as they migrated elsewhere. In my own work on processes of diasporization among Hindus in Mauritius (Eisenlohr 2006, 2015), I have called these an "ancestral chronotope" produced through acts of local pilgrimage and the cultivation of "ancestral" languages never used in everyday life. Such ancestral chronotopes bear great resemblances to Walter Benjamin's notion of "messianic time," a suspension of the differences between past, present, and future, all the more since Benjamin also linked messianic time to cyclically recurring festive events. Such events, for example Hindu pilgrimages on sacred days in the Hindu ritual calendar are a prime focus for the generation of diasporic forms of belonging for Mauritian Hindus. In those contexts, religious ritual, the recreation of an Indian Hindu sacred geography in Mauritius and the practice of "ancestral language" bring about the co-presence of Mauritian Hindus with virtuous Indian ancestors who migrated from India in the nineteenth century. As Hindu activists see it, these Indian ancestors successfully recreated Hindu ways of life under the most oppressive and adverse circumstances, and were ultimately rewarded for it with political ascendency and socio-economic mobility in postcolonial Mauritius. As is well known, Benjamin contrasted messianic time to the linear "empty, homogenous" time of historicism and also attached opposed political valencies with these two forms of temporality (Benjamin 1968). For Benjamin, linear, empty homogenous time tied to notions of progress was characteristic of bourgeois politics. According to him, political hope and liberation from established hierarchies and other forms of domination could be found in the unexpected irruption of messianic time.

It is highly tempting to follow Benjamin and to apply these links between contrasting politics and temporalities to my Mauritian example. Certainly, it would be easy to identify the bourgeois appreciation of socio-economic "progress" in the Hindu activist narrative of the phenomenal "rise" of the Hindus in Mauritius on account of their presumably Hindu moral virtues of thrift, family cohesion, long-suffering patience, and a corresponding work ethic. Such a politics of time legitimizes above all the position of a Hindu state bourgeoisie in control of much of the state apparatus and excludes all those Mauritians who for a variety of structural reasons have not been able to partake in the Mauritian "economic miracle" since the 1980s. Nevertheless, I would hesitate to identify those practices and events that generate "ancestral time" as those radically breaking up existing forms of authority and thus inhabiting the potential to completely restructure Mauritian politics along more just and inclusive lines. On the contrary, these practices play a crucial role in producing a politics of "ancestral cultures" based on standardized religious traditions with origins elsewhere as key components of full citizenship in Mauritius. They thereby help to legitimize the political dominance of a Hindu state bourgeoisie, while sidelining those who cannot claim ownership of a diasporic "ancestral culture" centered on religious difference, such as the descendants of African, Malagasy, and Indian slaves, known as Creoles. Performatively bringing about the co-presence of virtuous and heroic ancestors from India is thus not only compatible but may even facilitate a purist politics of exclusion along ethnic and religious lines. A sense of cultural citizenship that privileges membership in religiously grounded "ancestral cultures" with origins elsewhere puts all those who lack such affiliations at a disadvantage. In my research on Mauritius, I found that precisely the interplay between different temporalities is particularly effective in instantiating a rather exclusionist and purist politics of diaspora. This interplay is manifest in the oscillation between linear, progressive time as evident in narratives of the triumphant "rise" of the 
Hindus and ritually generated messianic-ancestral times that collapse the spatiotemporal remove between present-day Mauritian Hindus and their Indian ancestors. One of the lessons we can draw from this analysis is that hierarchies and exclusions in the making of diasporas are intertwined with not only one but also different regimes of temporality. This runs counter to Benjamin's intuition that temporalities along the lines of what he called messianic time have a liberatory character.

In his exploration of Sikh diasporas, Michael Nijhawan discusses a striking image, gripping in its sensory aspects, a 1985 painting of Rabindra Kaur Singh and Amrit Kaur Singh of the traumatic event of the 1984 storming of the Golden Temple in Amritsar by the Indian Army (Nijhawan 2016, 44-47). In a new, larger, version of the painting finished in 1998 we see not only the destroyed temple complex, pilgrims, and other civilians caught in a war-like situation, tanks entering the sacred complex, wounded bodies, and soldiers and militants fighting. We also see graphic depictions of atrocities, and above all the appearance of historical actors who did not live during the Indian Army's 1984 "Operation Blue Star," such as the eighteenth-century saint-soldier Baba Deep Singh, or persons that were not present at the events, such as Prime Minster Indira Gandhi, who ordered the attack on the temple complex, and who is depicted entering the scene on a tank, taking the shape of a five-headed monster reminiscent of the demon king Ravana (Nijhawan 2016, 46-47). In this painting of a traumatic event with characters from different times and places intermingling in one pictorial frame, one can see an irruption of Benjaminian "messianic time," collapsing the distinctions between past, present, and future, albeit in a way that is hardly redemptive. In its intense appeal to emotions, the painting simultaneously destabilizes memories of 1984 through the irruption of characters from other places and times and re-stabilizes them in a new narrative frame with strong moral loadings. In a way, the image exemplifies the recapture of messianic irruptions into progressive, linear time into new narratives and memories that draw boundaries between "us" and "them" in the construction of a moral order in trying to come to terms with a traumatic and violent event.

Reflecting on this image, I see some resemblances between the ideological recasting of the messianic irruptions the Singh brothers' painting depicts and the official capture of messianic co-presence of ancestors in state-supported Hindu Mauritian pilgrimage and ritual. This recapture of the messianic potential to upend and transform current politics and social arrangements occurs within the frame of Mauritian multiculturalism and its exclusions and imbalances. That is, as I have explained above, such recapture neutralizes the radical potential the interruption of linear narratives of progress and the "rise" of the Hindus in Mauritius holds in order to perpetuate many of the imbalances and exclusions of the present regime of Mauritian multiculturalism.

The invocation of Bergsonian rotational time points to a different way in which the disturbing of linear, progressive temporalities can be made fruitful in destabilizing social orders for the creation of new unexpected linkages and solidarities, across former hierarchies and lines of exclusion. In order to explain how this is possible, we need to take a closer look at what Bergson's rotational time is. In Matter and Memory, Bergson asks us to imagine memory as an inverted cone located between two planes, the plane of memory and the plane of action (Bergson [1896] 1911, 210-211). The base of the cone $(\mathrm{AB})$ aligns with the plane of memory, while the summit of the cone touches the plane of action at the point $\mathrm{S}$, which stands for the present perception a person has of his or 
her body. Memory unfolds as movements between the base and the summit of this cone, which represent the two unreachable extremes of a purely sensorimotor state at the inverted summit and a purely imaginative, dream-like memory without any trace of activity related to it at its base (Bergson [1896] 1911, 219). In psychic life, this vast collection of pure images is brought from the base of the cone, which contains all memories of the past, towards the point of action at its inverted summit. This movement can be executed to various degrees, resulting in different sections of memory made relevant for the present action a subject lives at a given moment. Bergson described these dynamics in the following terms:

But each section [of images of the past] is larger or smaller according to its nearness to the base or to the summit; and moreover each of these complete representations of the past brings to the light of consciousness only that which can fit into the sensorimotor state, and consequently that which resembles the present perception from the point of view of the action to be accomplished. In other words, memory, laden with the whole of the past, responds to the appeal of the present state by two simultaneous movements, one of translation, by which it moves in its entirety to meet experience, thus contracting more or less, though without dividing, with a view to action; the other of rotation upon itself, by which it turns towards the situation of the moment, presenting to it that side of itself which may prove to be the most useful.

Bergson [1896] 1911, 220

In situations like trying to remember a word in a foreign language memory contracts to be at the service of the action at hand in a movement, Bergson calls translation. For Bergson, the inverted cone also works like a telescope whose lenses we need to rotate until we catch images of the past that come into view unintentionally, which is another way in which dream-like images can be brought down towards the plane of action. In her work on the traumatic violence against Sikhs in Delhi that followed the assassination of Indira Gandhi in 1984, Veena Das argues that such images from the past, independently of subjective volition, come to descend to the level of action through this process of rotation. In the scenarios she discusses, such images from the past thereby turn into building blocks of rumors that in turn sanction deadly force (Das 2007, 108-109). This process of rotation is also productive of new forms of temporality, as is creates new relationships between the past and present, through actualizing certain regions of the virtuality that are the totality of the images of the past in the present. In adopting Bergson's analysis of time as an oscillation between the virtual and the actual, Das shows how the involuntary actualization of certain regions of the past through Bergsonian rotation of memory prepares the ground for a lethal breakdown of ordinary sociality.

Nevertheless, I suggest that the same process of rotation can also bring about actualizations of the past in the present that have a strongly redemptive potential, thereby helping to break the hold of certain ways of linking past and present that serve to underpin a status quo of hierarchization and exclusion. This can happen in an almost serendipitous way, independently of one's will, providing the raw material for counter-narratives and new images of society. One example from the diasporic context of Mauritius for such an alterative imaginary fed from the dream-like depths of memory is the literary and poetic invocation of "coolitude," a term coined as an analogue to negritude. This is a remembrance of the shared suffering and displacement of Indian "coolies" under the indenture in the colonial worlds of the Indian Ocean and their "transcultural" links and exchanges. To date, 
coolitude is mainly a literary vision that the Mauritian and French poet Khal Torabully formulated while writing from the diaspora, from France (Torabully 1992, Carter and Torabully 2002). So far, this vision has not had much of an impact on Mauritian society and politics. In poetic language, Torabully formulates a kind of counter-narrative to official Mauritian multiculturalism. By means of poetry and other literary creation, his work retrieves images from the past that uncover shared links between people that nowadays are considered to be part of separate "communities." He thereby re-actualizes shared experiences and solidarities that once existed but nowadays largely remain buried under the vision of Mauritius as a mosaic of clearly bounded ethnic and religious communities with separate origins that official multiculturalism and routine social life in Mauritius constantly reproduce. Coolitude as a poetic creation and remembrance of the past is a good example of the potential that images of the past, brought into the experience in unforeseen ways through what Bergson has described as the rotation of memory unto itself can have for a new kind of diasporic politics that escapes the strictures of multiculturalist compartmentalization. This literary vision stresses shared experiences and histories of displacement, suffering, small victories and perseverance under difficult circumstances among people of different origins in the colonial Indian Ocean world. It thus not only runs counter to the official Mauritian celebration of "ancestral cultures" tied to separate homelands and religious traditions. Implicitly, it also puts a finger on its omissions and exclusions. In the Mauritian context, the most urgent of these omissions and exclusions is the circumstance that not all Mauritians have recognized claims on diasporic "ancestral cultures" with their empowering effects in a regime of nation-building that highlights the origins of Mauritians in other parts of the world. Above all the descendants of slaves, the Creoles, lack such claims. The violence of slavery has destroyed ties with the places they came from and made it very difficult for them to reconstruct and reinvent connections to lands of origin as Mauritians of Indian and Chinese origins were able to do. Furthermore, the "ancestral cultures" that Mauritian multiculturalism privileges largely center on religion. Claiming to be a legitimate part of the Mauritian multicultural mosaic mostly involves claims of ownership of particular religious traditions. Making such claims to sovereign religious alterity is not a strategy available to Creoles, because they were converted to Catholicism in the context of slavery, while the Catholic Church has from its very beginnings in Mauritius been controlled and dominated by Franco-Mauritians, the former plantocrats. Coolitude has unearthed images of solidarity and commonality across what have become the ethnoreligious lines of Mauritian multiculturalism. In doing so, coolitude not only puts such boundaries in question but also helps to draw attention to the injustices and exclusions of the Mauritian multicultural regime.

Mauritian collective efforts at drawing links between the past and the present testify to the ideological narrowing of memory in the service of the politics of the day. In the examples from my research, I briefly presented above, such ideological narrowing is a process evident in both linear and in ancestral time. Both the linear narrative of the "rise" of the Hindus in Mauritius as well as the ritual occasions of co-presence with heroic ancestors from India are consonant with official multiculturalism, indeed the Hindu state bourgeoisie of Mauritius has been its main driving force. In their Hindu Mauritian contexts, both temporalities work towards a hardening of communal boundaries and the sidelining of histories of communality and solidarity across such boundaries. As I explained, this also involves ancestral time, a kind of temporality that bears a strong 
resemblance to Benjamin's messianic time. As Hindu Mauritian ancestral time testifies to the neutralizing of the redemptive potential that Benjamin saw as proper to messianic time, the reverse can also be said about Veena Das's pessimistic appropriation of Bergson's rotational time. Instead of propelling the deadly force of rumors in pogrom-like violence against religious minorities in India, coolitude as a vision from the Mauritian past can potentially engender more just and inclusive politics in a plural society.

\section{References}

Benjamin, Walter. 1968. Illuminations. New York: Harcourt, Brace \& World.

Bergson, Henri. 1911 [1896]. Matter and Memory. Translated by Nancy Margaret Paul and W. Scott Palmer. London: George Allen and Unwin.

Carter, Marina, and Khal Torabully. 2002. Coolitude: An Anthology of the Indian Labor Diaspora. London: Anthem.

Das, Veena. 2007. Life and Words: Violence and the Descent into the Ordinary. Berkeley: University of California Press.

Eisenlohr, Patrick. 2006. Little India: Diaspora, Time and Ethnolinguistic Belonging in Hindu Mauritius. Berkeley: University of California Press.

Eisenlohr, Patrick. 2015. "Mediating Disjunctures of Time: Ancestral Chronotopes in Ritual and Media Practices." Anthropological Quarterly 88 (2): 437-460.

Nijhawan, Michael. 2016. The Precarious Diasporas of Sikh and Ahmadiyya Generations: Violence, Memory, and Agency. New York: Palgrave Macmillan

Torabully, Khal. 1992. Cale d'étoiles, coolitude. La Réunion: Editions Azalées. 